\title{
Extra canal in permanent maxillary first molar in patients undergoing root canal treatment at a tertiary care dental hospital, Nepal
}

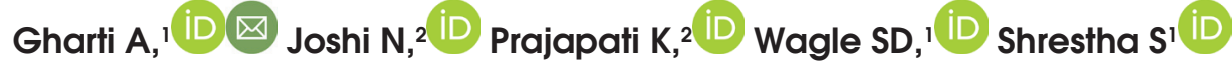 \\ ${ }^{1}$ Archana Gharti, Assistant Professor; ${ }^{2}$ Neera Joshi, Associate Professor; ${ }^{2}$ Kranti Prajapati, Associate Professor; ${ }^{1}$ Sharada Devi \\ Wagle, Assistant Professor; ${ }^{1}$ Suraj Shrestha, Assistant Professor, Department of Conservative Dentistry and Endodontics, \\ People's Dental College and Hospital, Kathmandu, Nepal.
}

\begin{abstract}
Background: Permanent maxillary first molar normally has three root canals but it can have extra root canals for which several studies were done in many parts of the globe. However, this type of study to explore extra canal is lagging in the context of Nepal.

Objectives: The objective was to determine the percentage of extra canal in permanent maxillary first molar in patients undergoing root canal treatment and to compare the same between male and female.

Methods: An analytical cross-sectional study was conducted in the department of conservative dentistry and endodontics of People's Dental College and Hospital from $20^{\text {th }}$ December 2019 to $20^{\text {th }}$ December 2020 after receiving ethical approval from Nepal Health Research Council on 16 th December 2019 (Ref. 1362). One hundred and eighty permanent maxillary first molar teeth without root canal calcification were enrolled. Convenient sampling was done. Access opening was done and all canal orifices were located and recorded. Data were analysed using Statistical Package for the Social Sciences (SPSS) version 22.0 with frequency table. Chi-square test was used for inferential statistics

Results: Out of 180 teeth, extra canals were present in 44 (24.4\%) having more numbers in male than in females. Extra canal was present in the mesiobuccal root.

Conclusion: Extra canal in the permanent maxillary first molar is present in Nepalese population with greater number in male than in female. Thus, exploration of the pulp chamber in search of an extra canal is necessary to prevent failure of root canal treatment.
\end{abstract}

Key words: Molar; Root canal; Root canal treatment.

Access this article online

Website: www.jkmc.com.np

DOI: https://doi.org/10.3126/jkmc.v10i1.38972

\section{HOW TO CITE}

Gharti A, Joshi N, Prajapati K, Wagle SD, Shrestha S. Extra canal in permanent maxillary first molar in patients undergoing root canal treatment at a tertiary care dental hospital, Nepal. J Kathmandu Med Coll. 2021;10(1):47-51.

\section{Address for correspondence}

\section{Dr. Archana Gharti}

Lecturer, Department of Conservative Dentistry and Endodontics, People's Dental College and Hospital, Kathmandu, Nepal.

E-mail: archanagharti@gmail.com

Copyright $\odot 2021$ Journal of Kathmandu Medical College (JKMC) ISSN: 2019-1785 (Print), 2091-1793 (Online)

\section{INTRODUCTION}

he maxillary first molar usually has three roots with three canals namely mesiobuccal, distobuccal, and palatal. The tooth can have variation in number of roots and root canals. The most frequent variation is having an extra canal in mesiobuccal root which was observed in several research with range of $50 \%$ to $90 \%$ varying in different age, gender, and population..$^{1-3}$ Such anatomical complexity of the permanent maxillary first molar may be unnoticed by novice practitioner.

Endodontic treatment involves exploration of all the root canals, cleaning and shaping and finally filling of these canals. Despite meticulous procedure, there can be failure. There are various reasons of endodontic failure. One of them is leaving the canals untreated during the procedure which would ultimately land into retreatment of the tooth. 4,5 Thus, having knowledge about the 
presence of extra canals would be beneficial during exploration of all the root canals.

This study was conducted with objective of determining the percentage of extra canal in the permanent maxillary first molar in patients undergoing root canal treatment (RCT) and to compare the same between male and female. Thus, the study will help to gain knowledge regarding the percentage of extra canals in the permanent maxillary first molar.

\section{METHODOLOGY}

This is an analytical cross sectional observational clinical study conducted from January 2020 to November 2020 , on 180 patients with age group 16-70 years attending Department of Conservative Dentistry and Endodontics of People's Dental College and Hospital. Sampling was done by convenience (non-probability) sampling technique and sample size was calculated to be 180 according to the reference article by Hartwell et al. ${ }^{2}$ Sample size was calculated for convenience (non-probability) sampling method ${ }^{6}$ using the formula: $\mathrm{n}=\mathrm{z}^{2} \mathrm{pq} / \mathrm{d}^{2}$; where, $\mathrm{n}=$ sample size; $\mathrm{z}=1.96$ at $95 \%$ confidence interval level; $p=70.2 \%$ (\% of extra canal); $q$ $=100-p=29.8 \% ; d=10 \%$ of $p=7.02$ (maximum tolerable error). Hence, $\mathrm{n}=(1.96)^{2 *}(70.2)(29.8) /(7.02)^{2}=163.07$. Taking $10 \%$ of $n=163.07 / 10=16.307$ (non-response); $n$ $=163.07+16.307=179.377=180$.

The study proposal was approved by Nepal Health Research Council on $16^{\text {th }}$ December 2019 (Ref. 1362). Patient of age 16-70 years with indication of RCT were included in the study. Preoperative radiographs were taken for evaluation (root morphology, number of canals and periapical status). Teeth with calcified pulp chamber and root canals and anyone not willing to participate in the study were excluded. Informed consent as well as written consent was taken in consent form for all the participants. Two endodontists conducted the procedure.

At first local anaesthesia was administered to the selected patient. Rubber dam application was done for isolation. An endodontic access opening was made using endo access bur and endo Z bur (Dentsply, Maillefer, Switzerland). The content of the pulp chamber was removed with endodontic spoon excavator. Debris and remaining pulp tissues were removed and copious irrigation was done using sodium hypochlorite (2.5\%) and normal saline. Then identification of all root canal orifices with sharp endodontic explorer (DG16 Endo Explorer, Hu-Friedy, United States) was done. Then, search of any extra canal was performed in dry and clear field along the dentinal map. Gentle removal of dentinal shelf from the mesiobuccal canal orifice towards palatal canal orifice was done to identify the possibility of a second mesiobuccal canal using E15D ultrasonic tip (NSK, Japan). The access cavity sometimes was modified to trapezoidal shape during this process. Then, all the root canals were negotiated with small stainless steel (ISO size .08, 10) hand files. Radiograph was taken with stainless steel hand file size 15 (Mani, Japan) in all canal. Clarke's techniques or SLOB (Same Lingual Opposite Buccal) technique was used for visualizing all canals separately making sure that no canal overlaps to each other. Number of root canals were verified by two endodontists. If there was a disagreement, a senior endodontist's opinion was sought. Then number of root canals was recorded in proforma. In subsequent visits, root canal treatment was completed. Data collected was entered in Microsoft Office Excel. Analysis of the data was done using IBM SPSS Statistics for Windows, version 22.0 (IBM Corp., Armonk, N.Y., USA).

\section{RESULTS}

Total of 180 samples were taken in study where 87 (48.3\%) were males and 93 (51.7\%) were females and the mean age was $36.87 \pm 13.485$ years. Three canals were present in 136 (75.6\%) tooth and four canals (extra canal) were present in $44(24.4 \%)$ as shown in Table 1.

In all the teeth having four canals, the fourth canal or the extra canal was $\mathrm{MB}_{2}$ canal which was present in 25 (28.7\%) in male and $19(20.4 \%)$ in female as depicted in Table 2.

Table 1: Basic demographic parameters

\begin{tabular}{lc}
\hline Demographic parameters & Frequency (\%) \\
Sex & \\
Male & $87(48.3)$ \\
Female & $93(51.7)$ \\
Number of canals & \\
Three & $136(75.6)$ \\
Four & $44(24.4)$ \\
\hline
\end{tabular}

Table 2: Association of extra canal with gender

\begin{tabular}{cccc}
\hline Sex & \multicolumn{2}{c}{$\begin{array}{c}\text { Presence of extra canal } \\
\text { Absent }\end{array}$} & $\begin{array}{c}\text { Present } \\
\text { p-value }\end{array}$ \\
\hline Male & $62(71.3 \%)$ & $25(28.7 \%)$ & 0.195 \\
Female & $74(79.6 \%)$ & $19(20.4 \%)$ & \\
Chi-square test & & \\
\hline
\end{tabular}




\section{DISCUSSION}

This is a clinical study performed in 180 patients undergoing root canal treatment in the Department of Conservative Dentistry and Endodontics of People's Dental College and Hospital. In this research, the prevalence of $24.4 \%$ of $\mathrm{MB}_{2}$ canal in maxillary first molar was noted. This canal was in higher percentage (28.7\%) in male patients than in female (20.4\%) patients. Mean age of patients with $\mathrm{MB}_{2}$ canal was 36.87 years. This canal was observed in adults in their third decade.

Prevalence of extra canal in permanent maxillary first molar is the field in the endodontic to be explored yet. Even though these types of studies have been conducted earlier but very few studies are there in Nepal. The relevance of this study lies in the treatment of first maxillary molar tooth which is submitted to frequent endodontic treatment, and moreover, it presents the highest failure rates because the clinician fails to locate, debride and obturate the $\mathrm{MB}_{2}$ canal in the mesiobuccal root. ${ }^{7-10}$ A study by Shetty et al., highlighted the fact that, the incidence of $\mathrm{MB}_{2}$ canal was more in maxillary first molars and that too presents in majority of cases and most of the unfilled $\mathrm{MB}_{2}$ canals had periapical radiolucencies. ${ }^{5}$

In current study we found out that $\mathrm{MB}_{2}$ canal was observed in young adults. This finding is seen in various other studies. Tripathi et al. found the mean age of participants as $35.75 \pm 16.39$ years. ${ }^{11}$ Al-Khriesat et al. observed the mean age of patients as 28.23 years. ${ }^{12}$ Shrestha et al. found the mean age of the sample as $33.53 \pm 14.60$ years. $^{3}$ These studies suggested that $\mathrm{MB}_{2}$ is observed in young patient. Young people usually have teeth with large and patent root canals. In old people there is higher chance of calcification related to age and other various long-standing insults. Thus, there is higher chance of finding extra root canal in young people than old people.

In present study, more of the male patients had $\mathrm{MB}_{2}$ canal than female patients. Al-Khriesat et al. in Jordanian population observed $\mathrm{MB}_{2}$ canal in $22.6 \%$ female and $23.5 \%$ male patients. ${ }^{12}$ This showed that male patient had more percentage of $\mathrm{MB}_{2}$ canal than in female patients which is similar to our study. In another study by Tripathi et al. extra canal in mesiobuccal root was found greater in females $(59.18 \%)$ in comparison to males $(40.82 \%){ }^{11}$ This result is in contrast to our study. This reflects that presence of extra canal may not be associated with the gender.

Similar study was conducted in 2019 by Tripathi et al. in Nepal which had a prevalence of $34.1 \%$ of extra canal in maxillary molar. ${ }^{11}$ Similar study done in Jordanian population in 2018 had $23.08 \%$ of extra canal in mesiobuccal root of maxillary molar. ${ }^{12}$ These studies were clinical study to find extra canal and the results were similar to our study.

Contrary to above studies, in another clinical examination of maxillary molars, $73.2 \%$ of $\mathrm{MB}_{2}$ canals were located routinely in maxillary first molar only. However, with experience and with the aid of operating microscope, $\mathrm{MB}_{2}$ canal was expected to be as high as $93 \% .^{13}$

Gary et al. had done a research in incidence of four canals in maxillary molar in 2007 in Newark, USA and found out to be $85 \%$ of $\mathrm{MB}_{2}$ canal. $^{2}$ The result was higher than present study. This might be due to the use of a dental operating microscope for detection of extra canal.

Combining magnification and illumination to locate extra canals is of utmost importance. ${ }^{14}$ The importance of the dental operating microscopes has already been established and its use for location of extra canals, including $\mathrm{MB}_{2}$ canal in maxillary molars is one important aspect. Furthermore, microscopes are helpful not only for documenting the cases, but also in improving communication with patients and referral to specific dentists. However, the learning curve of the microscope is long, due to its difficult ergonomics and the microscope is relatively expensive to have in one's clinical setup. ${ }^{15}$

One of the important studies using dental operating microscope was performed by Alacam et al. They sought out for $\mathrm{MB}_{2}$ canal in all teeth first without microscopy, then with the aid of the operating microscope and finally with the combined use of the operating microscope and ultrasonics. With these techniques, the $\mathrm{MB}_{2}$ canal was detected in $62 \%, 67 \%$, and $74 \%$ of the teeth, respectively. The results of this study suggested that the combined use of the operating microscope and ultrasonics increased the detection of $\mathrm{MB}_{2}$ canal in maxillary first permanent molars. $^{16}$

In this clinical study, we have clinically explored the pulp chamber floor to locate the canal orifice after detail evaluation of preoperative radiograph. Radiograph was obtained to confirm presence of extra canal. All canals with files in them are exposed for confirmation of usual and extra canals. This is truly based on clinical scenario of Nepal where we generally don't have easy access to advanced technology.

At present, cone beam computed tomography (CBCT) scan has become an important tool in modern 
endodontics. ${ }^{17}$ This imaging device has technology applicable in diagnosis and treatment planning for cases with complex anatomy. Different CBCT machines with different resolutions might lead to variation in results. ${ }^{18}$ Three-dimensional image of root canal morphology is obtained by CBCT. It is available only in very few centers in Kathmandu, Nepal. It is better to have few rather than not having one but in case of other parts of Nepal CBCT is unavailable. This is mainly due to its high cost. Thus, all these reasons lead us to limited availability of CBCT.

There are $\mathrm{CBCT}$ studies on $\mathrm{MB}_{2}$ canal in maxillary molars regarding its prevalence, canal configuration in different geographical area and different population. A retrospective $C B C T$ evaluation of 634 maxillary first molars was done. The $\mathrm{MB}_{2}$ canal was found in $53.78 \%$ of the cases that means it was present in approximately half of the cases. ${ }^{19}$ Another study on first maxillary molar teeth exhibited the highest prevalence of $\mathrm{MB}_{2}$ canal, $92 \%$ and $87 \%$, for right maxillary first molar and left maxillary first molar, respectively when CBCT was used..$^{20}$ In another retrospective study of 100 Dental $C T$, presence of $\mathrm{MB}_{2}$ canal in maxillary molars were present in $57 \%{ }^{21}$ So, these studies in CBCT showed higher prevalence of extra canals. This might be due to higher quality and three-dimensional image of tooth.

The study will help to gain knowledge regarding the percentage of extra canals in permanent maxillary first molar. This will add an essential data in field of dentistry

\section{REFERENCES}

1. Coelho MS, Lacerda MFLS, Silva MHC, Rios MA. Locating the second mesiobuccal canal in maxillary molars: challenges and solutions. Clin Cosmet Investig Dent. 2018;10:195-202. [PubMed | Full Text | DOI]

2. Hartwell G, Appelstein CM, Lyons WW, Guzek ME. The incidence of four canals in maxillary first molars: A clinical determination. J Am Dent Assoc. 2007 Oct;138(10):1344-6. [PubMed | Full Text | DOI]

3. Shrestha S, Sapkota MR, Saha A, Rajbhandari SM, Sapkota P. Occurrence of second mesio-buccal canal in maxillary first permanent molar: A CBCT study. Orthod J Nepal. 2017 Jun;7(1):39-43. [Full Text]

4. Iqbal A. The factors responsible for endodontic treatment failure in the permanent dentitions of the patients reported to the college of dentistry, the University of Aljouf, Kingdom of Saudi Arabia. J Clin Diagn Res. 2016 May;10(5):146-8. [PubMed | Full Text |DOI] and would come in relevance during treatment as well as during retreatment procedure. At the same time this study could have academical importance. Various studies have been conducted on extra canal but these types of clinical researches are very few in our country.

The study was conducted clinically without aid of magnifying tool. Better result would have been found if it was done under magnification. There can be different type of canal configuration of extra canal which was not taken into consideration in the study. The sample size was small and is a single centre study.

\section{CONCLUSION}

The study provides prevalence of extra canal in permanent maxillary first molar. This extra canal was found out to be present in mesiobuccal root and it is commonly known as second mesiobuccal canal $\left(\mathrm{MB}_{2}\right)$. Presence of extra root canal has to be kept in our concept before starting treatment and proper evaluation of diagnostic radiograph should be done. In addition to this, if clinician suspect the presence of extra canal and has difficulty in locating it then we can recommend CBCT along with use of microscope. Thus, we can prevent any extra canal from being unnoticed and missed which usually leads to failure of root canal treatment.

Conflict of interest: None

Source(s) of support: None

5. Shetty H, Sontakke S, Karjodkar F, Gupta P, Mandwe A, Banga KS. A cone beam computed tomography (CBCT) evaluation of MB2 canals in endodontically treated permanent maxillary molars. A retrospective study in Indian population. J Clin Exp Dent. 2017;9(1):e51-e55. [Full Text | DOI]

6. Fisher RA. On the interpretation of $x^{2}$ from contingency tables, and the calculation of $\mathrm{p}$. J R Stat Soc. 1922;85(1):87-94. [Full Text | DOI]

7. Vertucci FJ. Root canal morphology and its relationship to endodontic procedures. Endod Topics. 2005;10(1):3-29. [ Full Text | DOI]

8. Weine FS, Hayami S, Hata G, Toda T. Canal configuration of the mesiobuccal root of the maxillary first molar of a Japanese sub-population. Int Endod J. 1999;32(2):79-87. [PubMed | Full Text | DOI]

9. Wolcott J, Ishley D, Kennedy W, Johnson S, Minnich $\mathrm{S}$, Meyers J. A $5 \mathrm{yr}$ clinical investigation of second mesiobuccal canals in endodontically treated and 
retreated maxillary molars. J Endod. 2005;31(4):2624. [PubMed | Full Text | DOI]

10. Smadi L, Khraisat A. Detection of a second mesiobuccal canal in the mesiobuccal roots of maxillary first molar teeth. Oral Surg Oral Med Oral Pathol Oral Radiol Endod. 2007;103(3):e77-81. [PubMed | Full Text | DOI]

11. Tripathi R, Kashyap N, Khanduri N, Gupta S, Rohatgi S, Upadhyay M. Prevalence of additional canals in maxillary first molar in a Nepalese Population: A clinical study. Am J Biomed Sci \& Res. 2019 Jan;1(1):29-31. [Full Text | DOI]

12. Al-Khriesat AS, Al-Ghnanaeem MM, Al Saddi RA, AlQaisi RK, Masarwa NA, Khreisat IS. The incidence of a fourth canal in maxillary and mandibular first molars in a group of Jordanians: A clinical study. Journal of the Royal Medical Services. 2014 Dec;21(4):32-8. [Full Text | DOI]

13. Stropko JJ. Canal morphology of maxillary molars: clinical observations of canal configurations. J Endod. 1999;25(6):446-50. [PubMed | Full Text |DOI]

14. Hasan M, Raza Khan F. Determination of frequency of the second mesiobuccal canal in the permanent maxillary first molar teeth with magnification loupes (× 3.5). Int J Biomed Sci. 2014;10(3):201-7. [ Full Text ]

15. Bowers DJ, Glickman GN, Solomon ES, He J. Magnification's effect on endodontic fine motor skills. J Endod. 2010;36(7):1135-8. [PubMed | Full Text | DOI]
16. Alaçam T, Tinaz AC, Genç O, Kayaoglu G. Second mesiobuccal canal detection in maxillary first molars using microscopy and ultrasonics. Aust Endod J. 2008;34(3):106-9. [PubMed | Full Text | DOI]

17. Patel S, Durack C, Abella F, Shemesh H, Roig M, Lemberg K. Cone beam computed tomography in Endodontics - A review. Int Endod J. 2015;48(1):3-15. [PubMed | Full Text | DOI]

18. Bauman R, Scarfe W, Clark S, Morelli J, Scheetz J, Farman A. Ex vivo detection of mesiobuccal canals in maxillary molars using $\mathrm{CBCT}$ at four different isotropic voxel dimensions. Int Endod J. 2011;44(8):752-8. [PubMed | Full Text | DOI]

19. Faraj BM. The frequency of the second mesiobuccal canal in maxillary first molars among a sample of the Kurdistan Region-Iraq population - A retrospective cone-beam computed tomography evaluation. J Dent Sci. 2021;16(1):91-5. [Full Text | DOI]

20. Fernandes NA, Herbst D, Postma TC, Bunn BK. The prevalence of second canals in the mesiobuccal root of maxillary molars: A cone beam computed tomography study. Aust Endod J. 2019;45(1):46-50. [Full Text | DOI]

21. Rathi S, Patil J, Jaju PP. Detection of mesiobuccal canal in maxillary molars and distolingual canal in mandibular molars by dental CT: A retrospective study of 100 Cases. Int J Dent. 2010;2010:1-6. [Full Text | DOI] 